\title{
Characterisation of algogenic organic matter during an algal bloom and its implications for trihalomethane formation
}

Gough, R.S.; Gough, R.; Holliman, P.J.; Cooke, G.M.; Freeman, C.

\section{Sustainability of Water Quality and Ecology}

DOI:

10.1016/j.swaqe.2014.12.008

Published: 01/09/2015

Peer reviewed version

Cyswllt i'r cyhoeddiad / Link to publication

Dyfyniad o'r fersiwn a gyhoeddwyd / Citation for published version (APA):

Gough, R. S., Gough, R., Holliman, P. J., Cooke, G. M., \& Freeman, C. (2015). Characterisation of algogenic organic matter during an algal bloom and its implications for trihalomethane formation. Sustainability of Water Quality and Ecology, 6(September), 11-19.

https://doi.org/10.1016/j.swaqe.2014.12.008

\footnotetext{
Hawliau Cyffredinol / General rights

Copyright and moral rights for the publications made accessible in the public portal are retained by the authors and/or other copyright owners and it is a condition of accessing publications that users recognise and abide by the legal requirements associated with these rights.

- Users may download and print one copy of any publication from the public portal for the purpose of private study or research.

- You may not further distribute the material or use it for any profit-making activity or commercial gain

- You may freely distribute the URL identifying the publication in the public portal ?
}

Take down policy

If you believe that this document breaches copyright please contact us providing details, and we will remove access to the work immediately and investigate your claim. 
1 Characterisation of algogenic organic matter during an algal bloom 2 and its implications for trihalomethane formation

3 Rachel Gough*1, Peter J. Holliman ${ }^{2}$, Gavan M. Cooke ${ }^{1}$, Christopher Freeman ${ }^{1}$

$4{ }^{1}$ School of Biological Sciences, Bangor University, Deiniol Road, Bangor, Gwynedd, LL57 2UW, UK

$5 \quad{ }^{2}$ School of Chemistry, Bangor University, Deiniol Road, Bangor, Gwynedd, LL57 2UW, UK

$6 *$ Corresponding author: bss408@bangor.ac.uk. 
9 It is predicated that algal blooms will become an increasing problem under changing climatic conditions. This is particularly concerning for the potable water treatment industry since algogenic organic matter (AOM) in surface waters supplying water treatment works (WTWs) can cause a number of treatment issues. However, whilst previous studies have shown that AOM is distinct from terrigenous, humic-dominated organic matter, limited information exists relating to changes in the character of AOM during different algal growth phases. In this study, reservoir water containing dissolved organic carbon (DOC) dominated by humic material was enriched with nutrient medium to create an algal bloom. Over the course of the algal bloom, DOC was characterised using XADfractionation and UV absorbance measurements. In addition, the reactivity of DOC with chlorine both before and after XAD-fractionation was assessed using trihalomethane formation potential (THMFP) and bromine incorporation measurements to monitor whether THM yield and speciation varied between different growth phases. Characterisation of DOC during the algal bloom indicated a shift towards more hydrophilic, aliphatic (low specific UV absorbance; SUVA) DOC with the release of extracellular organic matter (EOM) and later intracellular organic matter (IOM) during cell lysis. XADfractionation results suggest that algae produce predominantly hydrophilic neutral (HPIN) DOC. In contrast to some existing research, our study shows a marked change in DOC reactivity over time with a reduction in standardised THMFP (STHMFP) and the initial rate of THM formation observed as the algal bloom progressed. However, bromine incorporation increased with culture age.

Key words: algogenic organic matter, dissolved organic carbon, potable water treatment, trihalomethane, XAD-fractionation.

\section{Introduction}

Algogenic organic matter (AOM), consisting of cells, extracellular organic matter (EOM; released from algal cells by diffusion) and intracellular organic matter (IOM; released from senescent algal cells during cell lysis), causes a number of issues in potable water treatment. These substances may contribute taste and odour, elevate total organic carbon (TOC) levels, increase coagulant and chlorine demand, cause membrane fouling and lead to an increase in potentially-harmful disinfection by-products (DBPs) such as trihalomethanes (THMs) (Bernhardt et al. 1991; Nguyen et al. 2005; Li et al. 2012). Some species of algae also produce toxic metabolites which present a public health risk (Žegura et al. 2011). The frequency and duration of algal blooms is predicted to increase as a result of climate change (Ritson et al. 2014). Thus, developing a better understanding of the 
changes in water quality and treatability during these episodes is important in allowing water treatment companies to adapt to a future treatment scenario.

Within the DOC pool, AOM shows a number of differences from natural organic matter (NOM) of terrigenous origin. Firstly, AOM has a higher nitrogen content than humic material due to its proteinaceous origin; TOC/TON ratios are reported as follows: NOM > EOM > IOM $\approx$ algal cells (Fang et al. 2010). In addition, AOM is more biodegradable and is characterised by lower molecular weights (MWs) (Leenheer \& Croue 2003; Nguyen et al. 2005; Fang et al. 2010). XAD-fractionation and specific UV absorbance (SUVA) measurements suggest that AOM tends to contain more hydrophilic and less aromatic carbon (Her et al. 2004; Leloup et al. 2013; Zhou et al. 2014). AOM characteristics also change as an algal bloom progresses through a series of growth phases (typically: lag phase, exponential growth phase, stationary phase and death phase). EOM is mostly released during the exponential growth phase and is composed of lower MW compounds such as glycolic and amino acids. IOM, released from senescent cells, mostly during the death phase, is composed of higher MW products such as polysaccharides (Huang et al. 2009).

Though algal cells tend to be associated with higher THM formation potential (THMFP), standardised for carbon concentration (STHMFP) than IOM and EOM (Yang et al. 2011), coagulation-flocculation is generally effective in removing algal cells during water treatment (Henderson et al. 2010).

Therefore, EOM and IOM represent the main algogenic THM precursors in potable water treatment. Under standardised chlorination conditions, the STHMFP of AOM varies between algal species, though contradictory results have been reported with regard to the relative reactivity of blue-green algae vs. green algae vs. diatoms (Plummer \& Edzwald 2001; Nguyen et al. 2005). Few studies have compared STHMFP values during different algal growth phases and contradictory results have been reported with regard to the reactivity of AOM as an algal bloom progresses. Nguyen et al. (2005) and Huang et al. (2009) concluded that DOC reactivity (STHMFP) did not vary significantly as a function of growth phase but only Huang et al. (2009) measured STHMFP during the death phase when large amounts of IOM are released into solution. Conversely, Yang et al. (2011) reported TOC and THMFP data that suggested a peak in STHMFP during the exponential growth phase. Furthermore, there are very limited data available for THM formation rates during different growth phases - an important consideration in a potable water treatment context since residence times of water in distribution systems are generally much shorter than the $7 \mathrm{~d}$ incubation periods typically used in the measurement of STHMFP. The speciation of THMs and particularly, the percentage of brominated THMs (BrTHMs) formed, is also reported to vary between species of algae and according to growth phase as a result of changing AOM character (Huang et al. 2009; Yang et al 2011) although there 
remains limited research in this area. This issue is important since BrTHMs are reported to be more carcinogenic than $\mathrm{CHCl}_{3}$ (Richardson et al. 2007). To our knowledge, bromine incorporation of individual XAD fractions during chlorination has not yet been assessed.

In this study, an algal bloom was generated in the laboratory using water collected from an upland drinking water reservoir by enriching with nutrient medium. A natural sample, as opposed to a pure algal culture was used to more accurately reflect field conditions and therefore better represent the water treatment scenario. Quantification and characterisation of DOC including XAD-fractionation and THMFP measurements were undertaken during the different growth phases. The data were used to assess how STHMFP, THM formation rate and bromine incorporation varied with algal growth phase and compared with the raw reservoir water.

\section{Methods}

\subsection{Site description and sample collection}

The water used in the study was collected from a UK upland drinking water reservoir. Its catchment comprises extensive areas of peatland (32\%) and grassland (38\%) as well as mainly-coniferous forest plantations (30\%) (Cohen 2009). Although algal populations are normally low in this reservoir, the drinking water provider has observed increased algal biomass in late spring/early summer. For this study, $10 \mathrm{~L}$ of water was collected from the surface (0-1 m depth) of the reservoir in May 2013 and transported immediately to the laboratory. Since the composition of natural surface water tends to fluctuate through time, the use of a natural sample in this study raises issues about repeatability. However, the use of this method was necessary to ensure that microbiological processes more accurately reflected those of a drinking water reservoir. In order to enable an appropriate comparison with existing research findings, we also sought to identify the species present in the algal bloom.

\subsection{Cultivation and measurement of algae}

A $30 \%$ Bold Basal medium with three-fold nitrogen and vitamins ( $3 N-B B M+V)(C C A P, U K)$ was made using $10 \mathrm{~L}$ of reservoir water. During a preliminary study, chlorophyll-a measurements indicated that this nutrient concentration was sufficient to produce an algal bloom. The solution was transferred to a $15 \mathrm{~L}$ glass jar, placed in a naturally-lit area of the laboratory and provided with aeration via an air pump connected to a ceramic air stone. 
Algal population density was monitored by measuring chlorophyll- $a$ concentration. These measurements were plotted over time and used to decide on the timing of the collection of larger sub-samples to represent distinct growth phases. For chlorophyll-a measurement, a $20 \mathrm{~mL}$ subsample was filtered through a Whatman GF/C filter which was then placed in a $15 \mathrm{~mL}$ centrifuge tube with 90\% acetone (Sigma-Aldrich, Dorset, UK). After refrigerating for $24 \mathrm{~h}$ at $4^{\circ} \mathrm{C}, 1.5 \mathrm{~mL}$ of the supernatant was pipetted into a $1.5 \mathrm{~mL}$ centrifuge vial. The solution was centrifuged at $1,800 \mathrm{~g}$ for 1 min and $347.5 \mu \mathrm{L}$ pipetted into a 96-well clear micro-plate to achieve a $1 \mathrm{~cm}$ path length. Absorbance at $\lambda=665$ and $750 \mathrm{~nm}$ was measured using a Molecular Devices SpectraMax M2e multidetection spectrophotometer (Molecular Devices, Berkshire, UK). Chlorophyll-a concentration was calculated using the following formula:

Chlorophyll- $a\left(\mathrm{mg} \mathrm{L}^{-1}\right)=11.9\left(\mathrm{Abs}_{665}-\mathrm{Abs}_{750}\right) \frac{v}{V p}$

Here $V$ is the volume filtered $(\mathrm{mL}), v$ is the volume of extract $(\mathrm{mL}), p$ is the pathlength $(\mathrm{cm})$ and 11.9 the specific absorbance coefficient of chlorophyll- $a$ in 90\% acetone (Golterman 1969).

\subsection{DOC and UV analysis}

For the measurement of DOC concentration and characteristics, samples were filtered through a $0.45 \mu \mathrm{m}$ membrane filter (Whatman). DOC measurements were carried out following acidification (to remove inorganic carbon) using a Thermalox TOC/TN analyser equipped with a non-dispersive infrared $\mathrm{CO}_{2}$ detector (Analytical Sciences, Cambridge, UK). UV absorbance measurements were made using a Molecular Devices SpectraMax M2e multi-detection spectrophotometer (Molecular Devices, Berkshire, UK) with aliquots of samples pipetted into a 96-well clear micro-plate. SUVA values were derived from the following formula: UV Abs $254\left(\mathrm{~cm}^{-1}\right) * 100 / \mathrm{DOC}\left(\mathrm{mg} \mathrm{L}^{-1}\right)$.

\subsection{Growth phase analysis}

Raw, exponential growth phase and death phase samples (Figure 1) underwent XAD-fractionation and STHMFP measurements. STHMFP was also measured for XAD fractions obtained from these three samples.

\section{XAD-fractionation}

Fractionation of DOC was achieved by resin adsorption using a method adapted from Thurman \& Malcolm (2003) and Marhaba et al. (2003). Samples were separated into five fractions: hydrophobic acid (HPOA), hydrophobic base (HPOB), hydrophilic acid (HPIA), hydrophilic base (HPIB) and 
hydrophilic neutral (HPIN) according to their sequential adsorption onto macroporous resins; Superlite ${ }^{\mathrm{TM}}$ DAX-8 ${ }^{\mathrm{TM}}$ resin and Amberlite ${ }^{\mathrm{TM}} \mathrm{XAD}-4^{\mathrm{TM}}$ resin (Sigma-Aldrich, Dorset, UK).

\section{Trihalomethane formation potential}

THMFP $_{7 d}$ denotes the quantity of THMs formed $\left(\mu \mathrm{g} \mathrm{L}^{-1}\right)$ following chlorination of a water sample for a $7 \mathrm{~d}$ incubation period at $25^{\circ} \mathrm{C}$. The method used was adapted from the Standing Committee of Analysts (1981) procedure. Samples were diluted to $1 \mathrm{mg} \mathrm{L}^{-1} \mathrm{DOC}$ to derive a standardised THMFP $7 \mathrm{~d}$ (STHMFP ${ }_{7 d}$ ) value which provides a measure of DOC reactivity. For chlorination, $97.5 \mathrm{~mL}$ of diluted sample was dosed with $2.0 \mathrm{~mL}$ of $0.5 \mathrm{M} \mathrm{KH}_{2} \mathrm{PO}_{4(\mathrm{aq})}$ to buffer the solution to $\mathrm{pH}$ 6.8. Samples were then dosed with $0.5 \mathrm{~mL}$ of $\mathrm{NaOCl}_{(\mathrm{aq})}$ to provide $5 \mathrm{mg}$ of free $\mathrm{Cl}$ per $\mathrm{mg}$ of DOC. After a $7 \mathrm{~d}$ incubation in the dark at $25^{\circ} \mathrm{C}$, the reaction was quenched using $0.4 \mathrm{~mL}$ of $0.8 \mathrm{M} \mathrm{Na}_{2} \mathrm{SO}_{3 \text { (aq) }}$ (all reagents supplied by Sigma-Aldrich, Dorset, UK). Extraction of the four chlorinated and brominated THM species $\left(\mathrm{CHCl}_{3}, \mathrm{CHBrCl}_{2}, \mathrm{CHBr}_{2} \mathrm{Cl}\right.$ and $\left.\mathrm{CHBr}_{3}\right)$ was achieved using direct immersion SPME followed by quantification using a Varian 450 GC coupled with an electron capture detector (Agilent Technologies, Berkshire, UK). THM concentrations were also measured after $1 \mathrm{~d}$ in order to compare the rate of THM formation between samples. The THM formation rate was calculated as STHMFP $\mathrm{P}_{1 \mathrm{~d}}$ as a percentage of STHMFP fd . The bromine incorporation factor (BIF) was calculated using the following formula:

$\mathrm{BIF}=\frac{\left[\mathrm{CHCl}_{2} \mathrm{Br}\right]+2\left[\mathrm{CHClBr}_{2}\right]+3\left[\mathrm{CHBr}_{3}\right]}{[\text { total THM }]} \quad$ (concentrations in $\mu \mathrm{mol} \mathrm{L}^{-1}$ ) $\quad$ (Yang et al. 2011)

\section{Results}

\subsection{Algal growth}

The raw water chlorophyll- $a$ concentration was $51 \mu \mathrm{g} \mathrm{L}^{-1}$. This began to increase sharply around day 13 and peaked at day 20 with $635 \mu^{-1}$ (Figure 1). Almost immediately the concentration began to fall again, returning to a chlorophyll- $a$ concentration similar to the raw water ( $70 \mu \mathrm{g} \mathrm{L}^{-1}$ on day 30 ). The profile of chlorophyll- $a$ concentration over time indicates three distinct growth phases in the algal bloom: a lag phase between days 0 and 14, an exponential growth phase between days 14 and 20 and a death phase between days 20 and 30. The green alga Ankistrodesmus sp. was found to dominate the algal bloom. The timing of sample collection for each growth phase is shown in Figure 1 by unshaded circles. 


\subsection{DOC and UV analysis}

159 Raw water DOC concentration was measured as $11.1 \mathrm{mg} \mathrm{L}^{-1}$. DOC concentration remained fairly 160 stable during the lag phase of the algal bloom but showed a sudden increase to $14.3 \mathrm{mg} \mathrm{L}^{-1}$ at the 161 beginning of the exponential growth phase (day 15) (Figure 1). DOC then decreased to slightly below the raw water concentration as the exponential growth phase proceeded. Around day 23, during the death phase, DOC concentration then began to increase dramatically, reaching a final concentration of $19.5 \mathrm{mg} \mathrm{L}^{-1}$ at day 30 .

At day 0 , SUVA measured $3.3 \mathrm{~L} \mathrm{mg}^{-1} \mathrm{~m}^{-1}$. This decreased during the lag phase to $2.3 \mathrm{~L} \mathrm{mg}^{-1} \mathrm{~m}^{-1}$ at day 15. SUVA then increased slightly during the exponential growth phase to $3.1 \mathrm{~L} \mathrm{mg}^{-1} \mathrm{~m}^{-1}$ at day 18 before decreasing steadily to a low of $1.2 \mathrm{~L} \mathrm{mg}^{-1} \mathrm{~m}^{-1}$ at day 30 (Figure 2).

\subsection{XAD-fractionation}

For raw, exponential growth phase and death phase samples, the HPOB and HPIB fractions combined represented $<5 \%$ of total DOC although their $\%$ contribution increased with culture age (Figure 3). The raw sample was dominated by HPOA DOC (57\%) with the HPIA fraction representing approximately one quarter (24\%) of the DOC and the HPIN fraction $17 \%$. The exponential growth phase sample was also dominated by the HPOA fraction (49\%) but showed a reduction in HPOA and HPIA compared with the raw sample and an increase in the HPIN fraction to $29 \%$. The death phase sample showed a dramatic difference in fractional character compared with the previous samples with the HPIN fraction becoming dominant (55\%), a further slight \% reduction in the HPIA fraction (to $14 \%$ ) and a more substantial reduction in the HPOA fraction (to $27 \%$ ).

\subsection{Trihalomethane formation potential}

Since the $\mathrm{STHMFP}_{7 \mathrm{~d}}$ measurement is standardised for DOC concentration, it can be used to compare DOC reactivity with chlorine between samples. For the un-fractionated samples, highest STHMFP $_{7 \mathrm{~d}}$ was observed for the raw sample ( $81 \mu \mathrm{g} \mathrm{THM} \mathrm{mg} \mathrm{DOC}-1 / 8.02 \mu \mathrm{mol}$ THM mmol DOC ${ }^{-1}$ ) followed by the exponential growth phase (66 $\mu \mathrm{g} \mathrm{THM} \mathrm{mg} \mathrm{DOC}^{-1} / 6.49 \mu \mathrm{mol} \mathrm{THM} \mathrm{mmol} \mathrm{DOC}^{-1}$ ) and death phase sample (31 $\mu \mathrm{g}$ THM mg DOC ${ }^{-1} / 3.02 \mu \mathrm{mol}$ THM mmol DOC $^{-1}$ ) (Figure 4a). Interestingly, for all samples analysed, including the un-fractionated samples and their constituent fractions (HPOA, HPIA and HPIN), STHMFP 7 showed the following sequence: raw > exponential > death (Figures 4a-4d). Highest $\mathrm{STHMFP}_{7 \mathrm{~d}}$ was recorded for the HPIA fraction of the raw water (122 $\mu \mathrm{g} \mathrm{THM} \mathrm{mg} \mathrm{DOC}^{-1}$ ) (Figure 4c) 
and lowest STHMFP $7 \mathrm{~d}$ for the HPIN fraction of the death phase sample (17 $\mu \mathrm{g} \mathrm{THM} \mathrm{mg} \mathrm{DOC}{ }^{-1}$ ) (Figure 4d).

191 Of the un-fractionated samples (Figure 4a), the raw sample showed a higher initial reaction rate

192 (STHMFP ${ }_{1 d}$ as a percentage of STHMFP $_{7 d}$ ) than the exponential growth phase and death phase 193 samples (60\% compared with $37 \%$ and $44 \%$, respectively). The fractionated samples, particularly the HPIA and HPIN fractions showed a greater range of initial reaction rates than the un-fractionated samples. Overall, the raw HPOA sample (Figure 4b) showed the highest reaction rate (64\%) and the death phase HPOA and HPIN fractions the lowest reaction rates ( $27 \%$ and $26 \%$, respectively) (Figures $4 b$ and $4 d)$.

Bromine incorporation

Bromine incorporation into THMs increased with culture age; for instance a bromine incorporation factor (BIF) of 0.018 was observed in the raw sample, compared to 0.026 in the exponential growth phase sample and 0.058 in the death phase sample (Figure 5). On average, BIF values for fractions showed the following trend: HPOA < HPIA < HPIN. However, there was substantial variation in BIF values for individual fractions between different samples (raw, exponential and death). For instance the death phase HPIN sample showed the highest BIF value (0.192), more than double any of the other samples.

\section{Discussion}

\subsection{Algal growth}

Chlorophyll-a measurements indicate low algal biomass in the raw water sample. Following nutrient enrichment and favourable light and temperature conditions in the laboratory, an algal bloom was generated resulting in a maximum chlorophyll-a concentration of $635 \mathrm{\mu g} \mathrm{L}^{-1}$. This was substantially lower than the peak chlorophyll-a concentrations reported previously for laboratory-based algal blooms. For example, Huang et al. (2009) reported maximum chlorophyll-a concentrations of approximately 2,700 $\mathrm{g} \mathrm{L}^{-1}$ and 2,100 $\mu \mathrm{g} \mathrm{L}^{-1}$ for Anabaena flos-aquae and Microcystis aeruginosa, respectively. This enhanced growth can be explained by a difference in culture conditions since Huang et al. (2009) used inoculated algae stock cultures and un-diluted nutrient growth media whereas here, a natural sample and diluted nutrient medium was used. Typically, four growth phases can be identified during an algal bloom. During the lag phase, indicated by static chlorophyll$a$ concentrations, algal cells use the newly-available nutrients to replenish internal nitrogen and 
phosphorus constituents. The exponential growth phase, characterised by a rapid increase in chlorophyll- $a$ concentration, involves rapid cell division and a dramatic increase in algal biomass. During this phase, significant amounts of EOM are released. The stationary phase, characterised once again by static chlorophyll- $a$ concentrations, occurs when the nutrient pool has been exhausted and cell division stops. Finally, the death phase, when chlorophyll- $a$ concentration declines occurs as a result of cell death. During the death phase large amounts of IOM are released due to widespread cell lysis. Our data did not show an identifiable stationary phase between the exponential and death phases. Previous studies have also reported the absence of a distinct stationary phase such as the Anabaena flos-aquae culture in Huang et al. (2009).

\subsection{DOC concentration}

Our DOC concentration data show a more erratic trend (see Figure 1) than those reported for inoculated algal cultures where DOC concentration has been reported to increase steadily with culture age (Huang et al. 2009; Yang et al. 2011). We suggest that this is due to our use of a natural sample and consequently, the competing effects of microbial degradation of DOC and algal DOC production during the algal bloom. Our aim in using natural samples was to more accurately reflect conditions in the field. The increase in DOC concentration observed during the early-exponential growth phase may reflect a significant release of EOM whilst the subsequent fall in DOC concentration during the late-exponential growth phase may be due to an increase in microbial population and the consequent degradation of EOM. The dramatic increase in DOC concentration during the late-death phase is likely to be caused by the rate of release of IOM during cell lysis exceeding the rate of microbial degradation.

\subsection{Specific UV absorbance}

SUVA is reported to correlate positively with DOC hydrophobicity and MW (Edzwald \& Tobiason 1999) and \% DOC aromaticity (Weishaar et al. 2003). Thus, the general reduction in SUVA during the course of the algal bloom is consistent with an increase in the relative contribution of low UVabsorbing, hydrophilic, aliphatic compounds typical of algogenic DOC, and a decrease in the relative contribution of humic constituents (Her et al. 2004; Yang et al. 2011; Huang et al. 2012). In addition, IOM is reported to be associated with lower SUVA values than EOM (Fang et al. 2010), the release of which may have contributed to the reduction in SUVA during the death phase. The slight recovery of SUVA during the exponential growth phase coincides with a decrease in DOC concentration. This may be explained by the preferential removal of low-SUVA algogenic DOC by microbial degradation since AOM is reported to be more biodegradable than humic material (Nguyen et al. 2005). 
252 The XAD-fractionation data reported here, which show a higher contribution of the HPIN fraction in

253 the exponential and death phase samples compared with the raw sample, are similar to results

254 reported previously. For example, Her et al. (2004) analysed AOM extracted from algal cells (IOM;

255 species unknown) and reported similar fractional character to our death phase result with $57.3 \%$

256 HPIN, 25.9\% HPOA and 16.8\% HPIA. Similar proportions were also reported by Henderson et al.

257 (2008) for EOM derived from four species (Chlorella vulgaris, Microcystis aeruginosa, Asterionella

258 formosa and Melosia sp.). For instance, in the stationary phase they reported that HPIN represented

$25957 \%$ or more and HPIA varied between $8 \%$ and $17 \%$. However, data presented in Leloup et al. (2013)

260 for Euglena gracilis indicated that the HPIN fraction dominates AOM during the exponential and

261 stationary growth phases (75\% and 69\%, respectively) and that the HPOA and HPIA fractions

262 correlated with increased cell mortality and release of IOM during later phases. They proposed that

263 the HPIN fraction initially formed may have been transformed to HPOA and HPIA according to

264 Stevenson's (1994) theory of polyphenols. By contrast, our data suggest that the contribution of

265 HPIN increases with cell mortality and that the contribution of HPOA and HPIA decreases with

266 culture age. This difference may be due to the different algal species involved. However, a

267 comparison of IOM from different species cultured under standardised conditions would be

268 necessary to confirm this.

\subsection{Trihalomethane formation potential}

Our STHMFP ${ }_{7 d}$ data, which show a marked decrease as the algal bloom progressed, conflict with the results of previous studies which indicate that STHMFP does not vary as a function of growth phase (Nguyen et al. 2005; Huang et al. 2009). This may be due to the presence of different algal species in our culture. Alternatively, differences in culture conditions may be responsible. Indeed, Nguyen et al. (2005) show that STHMFP for the same species may vary depending on the conditions in which the algae are cultured.

277 High STHMFP $7 \mathrm{~d}$ in the un-fractionated raw water sample $\left(81 \mu \mathrm{g} \mathrm{THM} \mathrm{mg} \mathrm{DOC}{ }^{-1}\right)$ can be explained by the dominance of allochthonous humic material which is reported to react more readily to form THMs than algogenic DOC (Fang et al. 2010). This enhanced reactivity may be linked to its higher hydrophobicity and aromaticity (and hence high SUVA), both of which are reported to have a positive relationship with STHMFP (Edzwald et al. 1985; Chow et al. 2005). Reduced reactivity in the 
un-fractionated samples with culture age may be due to microbial degradation of humic DOC and an increased contribution from hydrophilic, aliphatic, low SUVA DOC with the release of EOM, and later IOM, into the DOC pool. Reduced STHMFP ${ }_{7 d}$ between the exponential and death phase samples can also be explained by the release of IOM from senescent cells in the death phase. Indeed, Li et al. (2012) report lower STHMFP for IOM than EOM extracted from Microcystis aeruginosa during the exponential growth phase. Zhou et al. (2014) however reported that the chloroform yield for IOM was approximately double that of EOM (both extracted from Microcystis aeruginosa). Our exponential samples also show higher STHMFP 7d $_{\text {values }}\left(66 \mu \mathrm{g}\right.$ THM mg DOC $^{-1} / 6.49 \mu \mathrm{mol}$ THM mmol DOC $^{-1}$ ) than some of those reported previously. For example, Yang et al. (2011) report THM yields of 1.31 and $1.51 \mu \mathrm{mol}$ THM mmol DOC ${ }^{-1}$ for Microcystis aeruginosa and Chlorella vulgaris, respectively during the exponential growth phase ( 3 d incubation, $\left.\mathrm{pH} 7.2,22 \pm 1^{\circ} \mathrm{C}\right)$. Fang et al. (2010) report a THM yield of $\sim 16 \mu \mathrm{g}$ THM mg DOC ${ }^{-1}$ for Microcystis aeruginosa during the stationary growth phase ( $3 \mathrm{~d}$ incubation, $\mathrm{pH} 6.8,22 \pm 1^{\circ} \mathrm{C}$ ). The higher THM yields observed in the present study may be due to the longer incubation period used ( $7 \mathrm{~d}$ ) and/or the presence of residual humic material from the original raw water sample. The consistency in the $\mathrm{STHMFP}_{7 d}$ results in terms of the relative reactivity of raw, exponential and death phase samples (raw > exponential > death) suggests that the reduced reactivity of the un-fractionated samples with culture age is partly due to reduced reactivity in all three of their main constituent fractions, rather than merely the result of a change in the proportions of the different fractions.

Although lower STHMFP 7 was observed for algogenic DOC compared with humic DOC in this study, it should be noted that, whereas DOC with high hydrophobicity, HMW and high SUVA such as humic material is reported to be amenable to removal by coagulation, LMW hydrophilic, low SUVA DOC is reported to be relatively more recalcitrant (Sharp et al. 2006; Chow et al. 2009). In addition, algogenic DOC is reported to be associated with higher nitrogenous DBP (NDBP) production than humic DOC (Bond et al. 2011; Ritson et al. 2014). Thus the relationship between DOC origin and THM yield in drinking water is not straightforward.

\section{Rate of THM formation}

In the present study STHMFP ${ }_{1 d}$ as a percentage of STHMFP $_{7 d}$ was used to represent THM formation rate. The initial rate of THM formation was found to decrease as the algal bloom progressed and DOC origin shifted from predominantly humic to predominantly algogenic. Thus, in terms of THM concentrations at the point of delivery to the consumer, it appears that chlorination of AOM may be less problematic than chlorination of humic material in this reservoir water due to its lower initial reaction rate. Previous studies have identified fast- and slow-reacting THM precursors based on DOC 
functionality (Gallard \& von Gunten 2002; Dickenson et al. 2008). Thus, the algogenic DOC in this study appears to contain relatively more slow-reacting THM precursors than humic DOC. In the fractionated samples, the death phase HPOA and HPIN fractions showed particularly low initial reaction rates; $\mathrm{STHMFP}_{1 \mathrm{~d}}$ as a percentage of $\mathrm{STHMFP}_{7 \mathrm{~d}}$ was $27 \%$ and $26 \%$, respectively, which corresponds with the low reaction rate of the un-fractionated death phase sample.

\section{Bromine incorporation}

The increased bromine incorporation in the un-fractionated samples with culture age in this study can be explained by shifting DOC character during successive growth phases. Previous studies have shown a negative relationship between bromine incorporation and SUVA, hydrophobicity and aromaticity (Heller-Grossman et al. 1993; Kitis et al. 2002; Teksoy et al. 2008). XAD fractional character and SUVA measurements indicate a shift towards lower SUVA, aromaticity and hydrophobicity as the algal bloom progressed due to the release of EOM during the exponential growth phase, and IOM during the death phase. The speciation of THMs is important because BrTHMs are reported to more carcinogenic than $\mathrm{CHCl}_{3}$ (Richardson et al. 2007). Our data suggests therefore, that changing speciation of THMs with culture age may increase the health risks associated with chlorination of dissolved AOM. The BIF data reported here contrast with the findings of Huang et al. (2009) who report that the BIF of dissolved AOM for Anabaena flos-aquae remained fairly stable throughout the algal bloom but for Microcystis aeruginosa, fell as the bloom progressed and made a slight recovery during the death phase. This trend, it was suggested, was due to a decrease in hydrophilic content with culture age.

To our knowledge bromine incorporation in XAD fractions of AOM has not been studied previously. The high BIF values associated with the HPIN fraction can be explained by its low SUVA, hydrophobicity and aromaticity. The variation in BIF values within the same fraction over time suggests that variation in BIF in the un-fractionated samples were not simply the result of changes in the fractional character, but also relate to changes in the reactivity of DOC within individual fractions. The BIF values reported in this study $(0.018-0.192)$ are very low compared with those reported previously. For example, Yang et al. (2011) report median BIF values of 1.4 and 1.3 for dissolved AOM associated with Chlorella vulgaris and Microcystis aeruginosa, respectively. Those reported by Huang et al. (2009) varied between $\sim 1.1$ and $\sim 1.8$. Kitis et al. (2002) report BIF values of $\sim 0.9$ and $\sim 1.7$ for a high SUVA water (Myrtle Beach, California) and a low-SUVA water (Tomhannock reservoir, New York). However, all of these measurements involved spiking with bromine, whereas in the present study, bromine was derived from the ambient bromide level in the samples and from the $c a .1 \% \mathrm{Br}_{2}$ as a production impurity in $\mathrm{NaOCl}$. Bromine incorporation in a real 
treatment scenario is likely to be higher due to the lower chlorine residuals involved and as a result, higher $\mathrm{Br}^{-}: \mathrm{Cl}_{2}$ ratio (Bond et al. 2014).

Overall our results emphasize the importance of effective AOM removal, particularly during the death phase, due to the increase in brominated THM species as the bloom progressed. Whilst coagulation-flocculation is effective in removing algal cells, EOM and IOM are less amenable to removal (Henderson et al. 2010). Ultrafiltration and biodegradation have been identified as successful methods of EOM and IOM removal (Zhou et al. 2014). It is likely that many WTWs will have to adopt these technologies as the problem of algal blooms increases.

\section{Conclusions}

In this study an algal bloom, dominated by the green alga Ankistrodesmus sp., was generated using an upland reservoir sample and monitored using chlorophyll- $a$ measurements. Our use of natural samples as opposed to pure algal cultures was designed to more accurately reflect field conditions. Three distinct growth phases were identifiable (lag, exponential and death) during which subsamples were collected. These were analysed to compare DOC concentration and character between growth phases. In particular, we investigated the reactivity of these samples with chlorine to assess the impact of algogenic DOC on THM yield in potable water. Potential variations in AOM reactivity between growth phases has received little attention in the literature.

Our data support the findings of previous studies showing lower STHMFP associated with algogenic DOC compared with humic DOC. However, in contrast to some previous studies, the present experiment also found that STHMFP varied markedly between different growth phases. STHMFP was found to decrease as the algal bloom progressed consistent with the following order of reactivity: IOM < EOM < NOM. In addition, it was found that algogenic DOC produced both during the exponential and death phases formed THMs at a lower initial rate than humic DOC, as indicated by the \% of THMFP $7 \mathrm{~d}$ formed within the first $24 \mathrm{~h}$. These data suggest that algogenic DOC has a lower THM yield than humic DOC. However, when assessing the relative risks associated with AOM and humic DOC in terms of THM formation, the more recalcitrant nature of algogenic DOC should be considered.

In addition, our data show that formation of BrTHMs, considered to be more carcinogenic, varies as follows: IOM > EOM > NOM. Thus, despite its lower THM yield, AOM removal during water treatment should be considered a priority, particularly during the death phase of an algal bloom. Measurement of bromine incorporation for different XAD fractions was carried out for the first time 
in this study. The results suggest that increased bromine incorporation with culture age results not only from a change in XAD-fractional character but also from a change in the reactivity of individual fractions over time.

Though several previous studies have considered the fractional character of AOM, by analysing AOM during both the exponential growth phase and the death phase, our results provide a more detailed assessment of the impact of algae on the fractional character of the DOC pool. Whilst our data support the findings of previous research showing the dominance of the HPIN fraction in algogenic DOC, it disagrees with the suggestion of a correlation between cell mortality and the release of HPOA and HPIA fractions. Instead, this study indicates that senescent algal cells predominantly contribute HPIN material to the DOC pool.

\section{Acknowledgements}

This research was part-funded by the European Social Fund (ESF) through the European Union's Convergence programme administered by the Welsh Government. Match funding and access to water samples and water quality data was provided by Dŵr Cymru Welsh Water (DCWW). Christopher Freeman and Peter Holliman acknowledge funding from NERC under the first EU ERA-EnvHealth call (FP7-ENV-2007- CSA-1.2.3-01). We would like to thank Dr David Hughes, School of Chemistry, Bangor University, for assistance with the fractionation procedure and Nigel Brown, School of Biological Sciences, Bangor University for algae identification.

\section{References}

Bernhardt, H.; H. Schell, O. Hoyer, B Lusse, Influence of algogenic organic substances on flocculation and filtration, Z. Wasser-Abwasser-Forsch. 1 (1991) 41-57.

Bond, T.; J. Huang, M.R. Templeton, N.J.D. Graham, Occurrence and control of nitrogenous disinfection by-products in drinking water - a review, Water Res. 45 (2011) 4341-4354.

Bond, T.; J. Huang, N.J.D. Graham, M.R. Templeton, Examining the interrelationship between DOC, bromide and chlorine dose on DBP formation in drinking water - a case study, Sci. Total Environ. 470471 (2014) 469-479.

Chow, A.T.; S. Gao, R.A. Dahlgren, Physical and chemical fractionation of dissolved organic matter and trihalomethane precursors: a review, J. Water Supply: Res. Technol.-AQUA 54 (2005) 475-507.

Chow, C.W.K.; J.A. Van Leeuwen, R. Fabris, M. Drikas, Optimised coagulation using aluminium sulfate for the removal of dissolved organic carbon, Desalination 245 (2009) 120-134.

Cohen, I. Spatial and temporal influences on the terrigenous carbon in reservoirs within peat-rich catchments, MPhil thesis, Bangor University 2009. 
Dickenson, E.R.V.; R.S. Summers, J. Croue, H. Gallard, Haloacetic acid and trihalomethane formation

412 from the chlorination and bromination of aliphatic beta-dicarbonyl acid model compounds, Environ.

413 Sci. Technol. 42 (2008) 3226-3233.

414 Edzwald, J.K.; W.C. Becker, K.L. Wattier, Surrogate parameters for monitoring organic matter and 415 THM precursors, J. Am. Water Works Assoc. 77 (1985) 122-132.

416 Edzwald, J.K.; J.E. Tobiason, Enhanced coagulation: US requirements and a broader view, Water Sci.

417 Technol. 40 (1999) 63-70.

418 Fang, J.; X. Yang, J. Ma, C. Shang, Q. Zhao, Characterization of algal organic matter and formation of 419 DBPs from chlor(am)ination, Water Res. 44 (2010) 5897-5906.

420 Gallard, H.; U. von Gunten, Chlorination of natural organic matter: kinetics of chlorination and of 421 THM formation, Water Res. 36 (2002) 65-74.

422 Golterman, H.L. Methods for Physical and Chemical Analysis of Fresh Waters (International Biological 423 Program Handbook no. 8), Blackwell, London, 1969.

424 Heller-Grossman, L.; J. Manka, B. Limoni-Relis, M. Rebhun, Formation and distribution of haloacetic 425 acids, THM and TOX in chlorination of bromide-rich lake water, Water Res. 27 (1993) 1323-1331.

426 Henderson, R.K.; A. Baker, S.A. Parsons, B. Jefferson, Characterisation of algogenic organic matter 427 extracted from cyanobacteria, green algae and diatoms, Water Res. 42 (2008) 3435-3445.

428 Henderson, R.K.; S.A. Parsons, B. Jefferson, The impact of differing cell and algogenic organic matter 429 (AOM) characteristics on the coagulation and floatation of algae, Water Res. 44 (2010) 3617-3624.

430 Her, N.; G. Amy, H.R. Park, M. Song, Characterizing algogenic organic matter (AOM) and evaluating 431 associated NF membrane fouling, Water Res. 38 (2004) 1427-1438.

432 Huang, J.; N.J.D. Graham, M.R. Templeton, Y. Zhang, C. Collins, M. Nieuwenhuijsen, A comparison of 433 the role of two blue-green algae in THM and HAA formation, Water Res. 43 (2009) 3009-3018.

434 Huang, W.; H. Chu, H, B. Dong, Characteristics of algogenic organic matter generated under different 435 nutrient conditions and subsequent impact on microfiltration membrane fouling, Desalination 293 436 (2012) 104-111.

437 Kitis, M.; T. Karanfil, A. Wigton, J.E. Kilduff, Probing reactivity of dissolved organic matter for 438 disinfection by-product formation using XAD-8 resin adsorption and ultrafiltration fractionation, 439 Water Res. 36 (2002) 3834-3848.

440 Leenheer, J.A.; J. Croue, Characterising dissolved aquatic organic matter, Environ. Sci. Technol. 37 441 (2003) 18A-26A.

442 Leloup, M.; R. Nicolau, V. Pallier, C. Yéprémian, G. Feuillade-Cathalifaud, Organic matter produced by 443 algae and cyanobacteria: quantitative and qualitative characterization, J. Environ. Sci. 25 (2013) 444 1089-1097. 
Li, L.; N. Gao, Y. Deng, J. Yao, K. Zhang, Characterization of intracellular \& extracellular algae organic matters (AOM) of Microcystic aeruginosa and formation of AOM-associated disinfection byproducts and odor \& taste compounds, Water Res. 46 (2012) 1233-1240.

448 Marhaba, T.F.; Y. Pu, K. Bengraine, Modified dissolved organic matter fractionation technique for natural water, J. Hazard. Mater. 101 (2003) 43-53.

Richardson, S.D.; M.J. Plewa, E.D. Wagner, R. Schoeny, D.M. Demarini, Occurrence, genotoxicity, and carcinogenicity of regulated and emerging disinfection by-products in drinking water: a review and roadmap for research, Mutat. Res. 636 (2007) 178-242.

Ritson, J.P.; N.J.D. Graham, M.R. Templeton, J.M. Clark, R. Gough, C. Freeman, The impact of climate change on the treatability of dissolved organic matter (DOM) in upland water supplies: a UK perspective. Sci. Total Environ. 473-474 (2014) 714-730. moorland peat catchment on coagulation with iron and aluminium salts, Environ. Pollut. 140 (2006) 436-443.

Stevenson, S.J. Humus Chemistry: Genesis, Composition, Reactions, second ed., Wiley, New York, 1994.

467 Teksoy, A.; A., U. Alkan, H.S. Başkaya, Influence of the treatment process combinations on the formation of THM species in water, Sep. Purif. Technol. 61 (2008) 447-454.

469 Thurman, E.M.; R.L. Malcolm, Preparative isolation of aquatic humic substances, Environ. Sci. 470 Technol. 15 (1981) 463-466.

471 Weishaar, J.L.; G.R. Aiken, B.A. Bergamaschi, M.S. Fram, R. Fujii, K. Mopper, Evaluation of specific 472 ultraviolet absorbance as an indicator of the chemical composition and reactivity of dissolved 473 organic carbon, Environ. Sci. Technol. 37 (2003) 4702-4708.

474 Yang, X.; W. Guo, Q. Shen, Formation of disinfection byproducts from chlor(am)ination of algal 475 organic matter, J. Hazard. Mater. 197 (2011) 378-388.

476 Žegura, B.; A. Štraser, M. Filipič, Genotoxicity and potential carcinogenicity of cyanobacterial toxins 477 a review, Mut. Res., Rev. Mutat. Res. 727 (2011) 16-41.

478 Zhou, S.; Y. Shao, N. Gao, Y. Deng, L. Li, J. Deng, C. Tan, Characterization of algal organic matters of 479 Microcystis aeruginosa: Biodegradability, DBP formation and membrane fouling potential, Water 480 Res. 52 (2014) 199-207. 
482

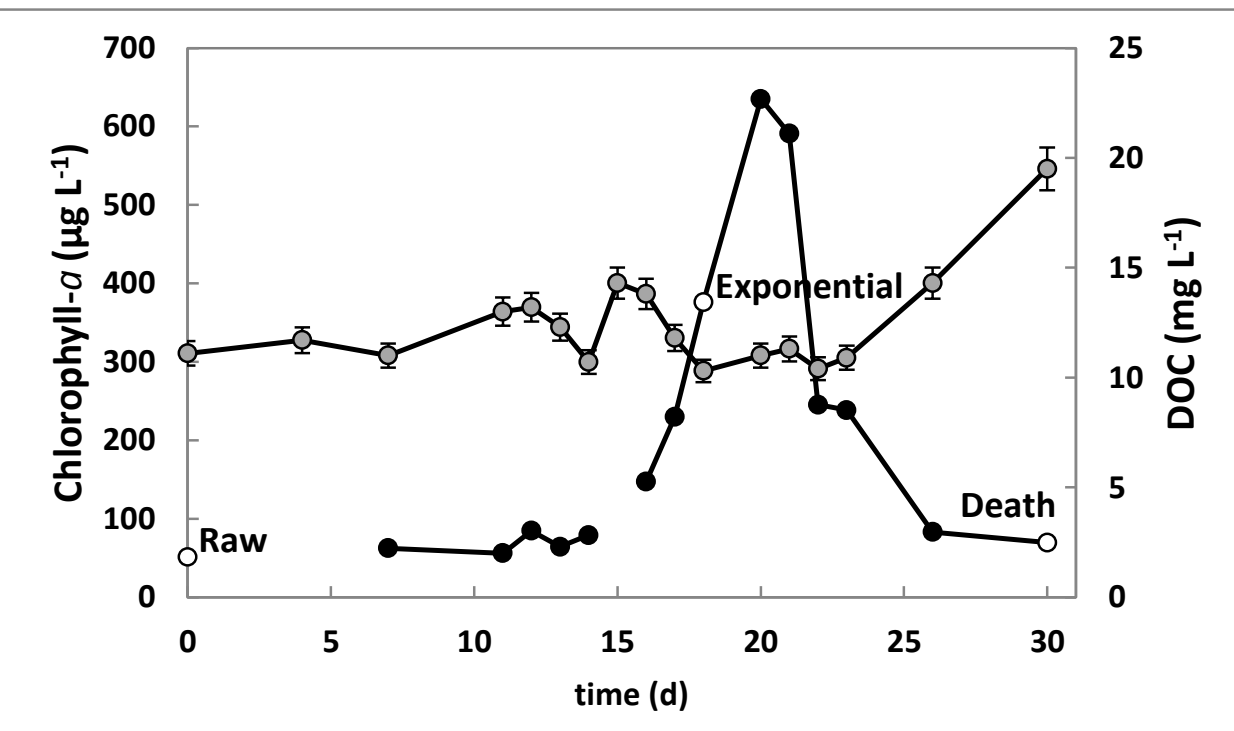

Figure 1. Chlorophyll- $a$ concentration (black markers) plotted with DOC concentration (grey markers) over the course of the algal bloom. Unshaded markers show timing of collection of raw, exponential growth phase and death phase samples. Error bars represent 5\% CV.

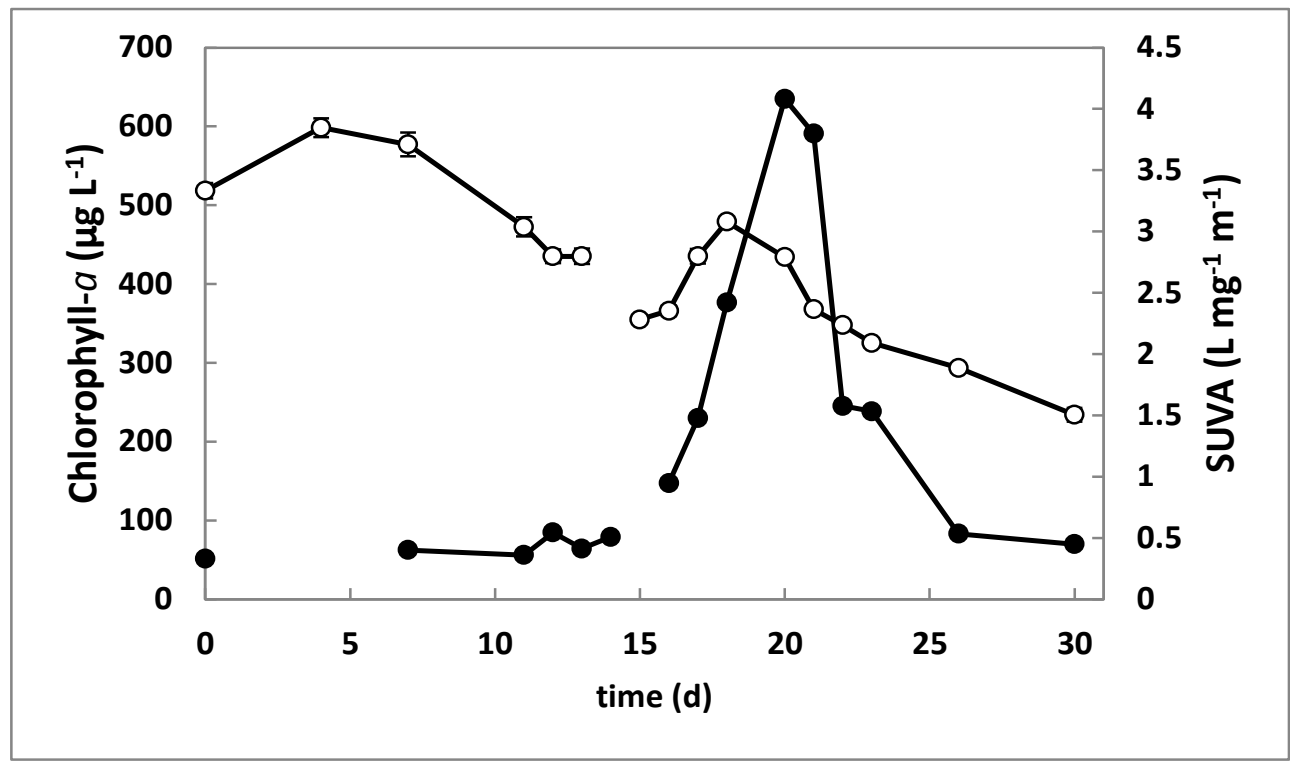

Figure 2. Chlorophyll- $a$ concentration (black markers) plotted with SUVA (white markers) over the course of the algal bloom. Error bars represent the standard error. 


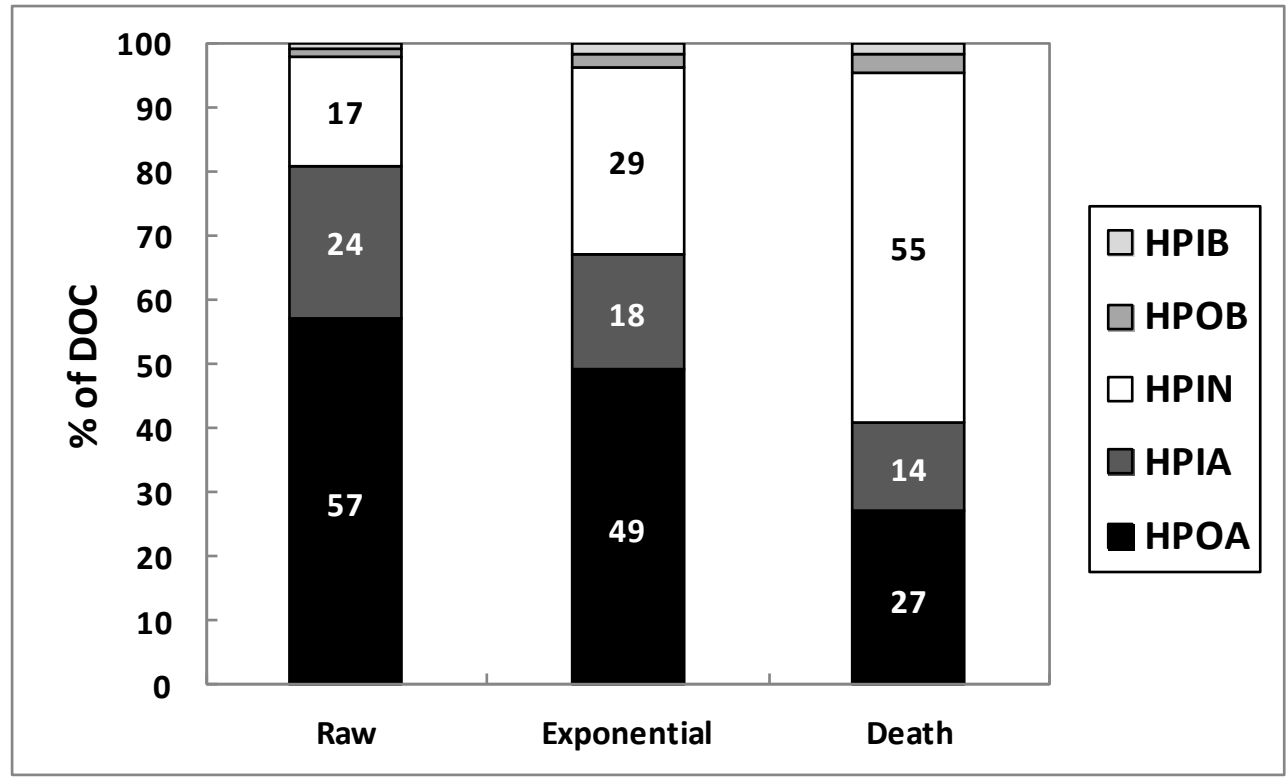

Figure 3. \% contribution of HPOA, HPIA, HPIN, HPOB and HPIB fractions to the total recovered DOC following fractionation of raw, exponential growth phase and death phase samples. 

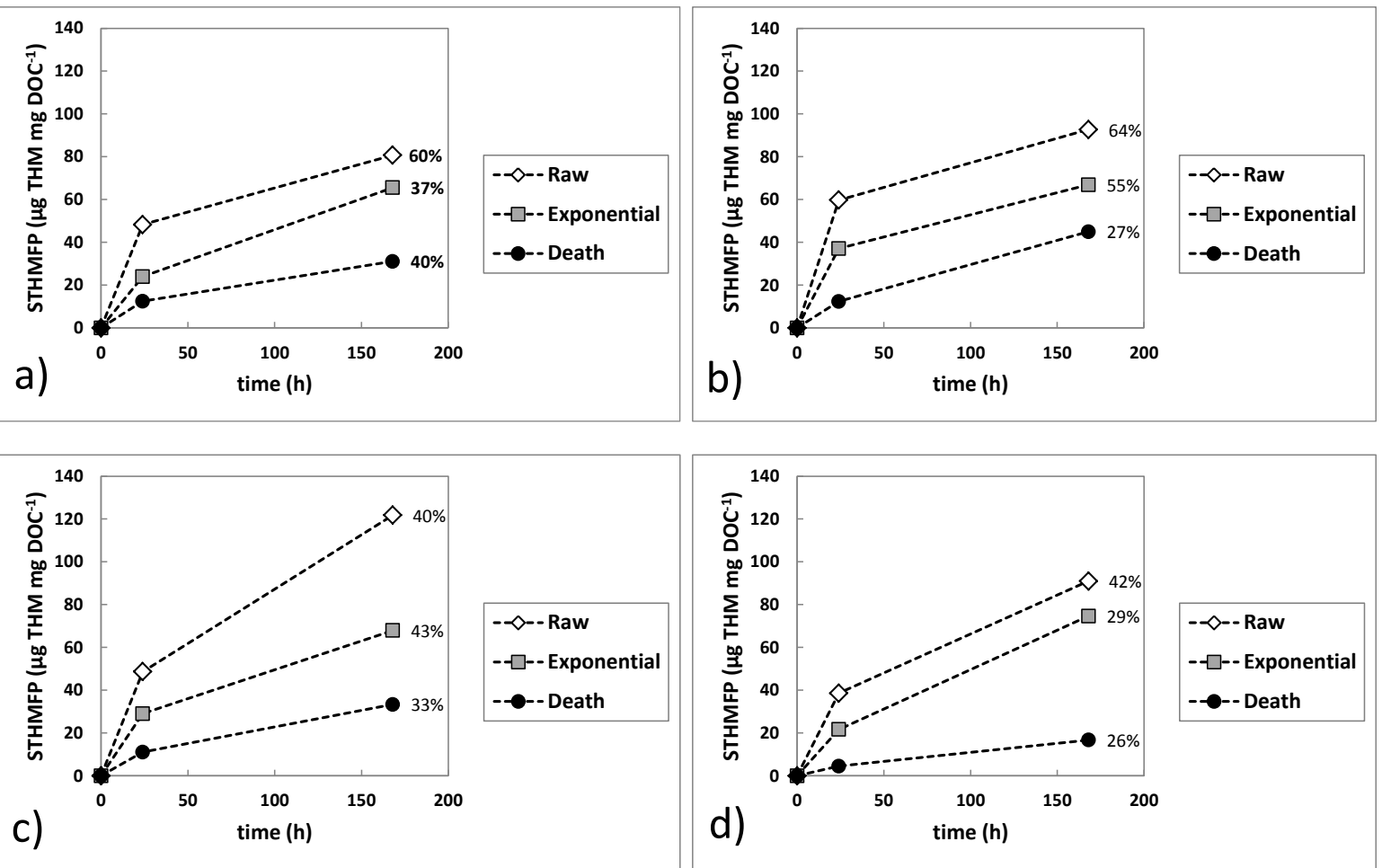

Figure 4. Profile of STHMFP over a $7 \mathrm{~d}$ incubation period following chlorination of the raw, exponential growth phase and death phase samples including in their unfractionated state (a) and their constituent fractions; HPOA (b), HPIA (c) and HPIN (d). STHMFP ${ }_{1 d}$ as a percentage of STHMFP $7 d$ is also shown.

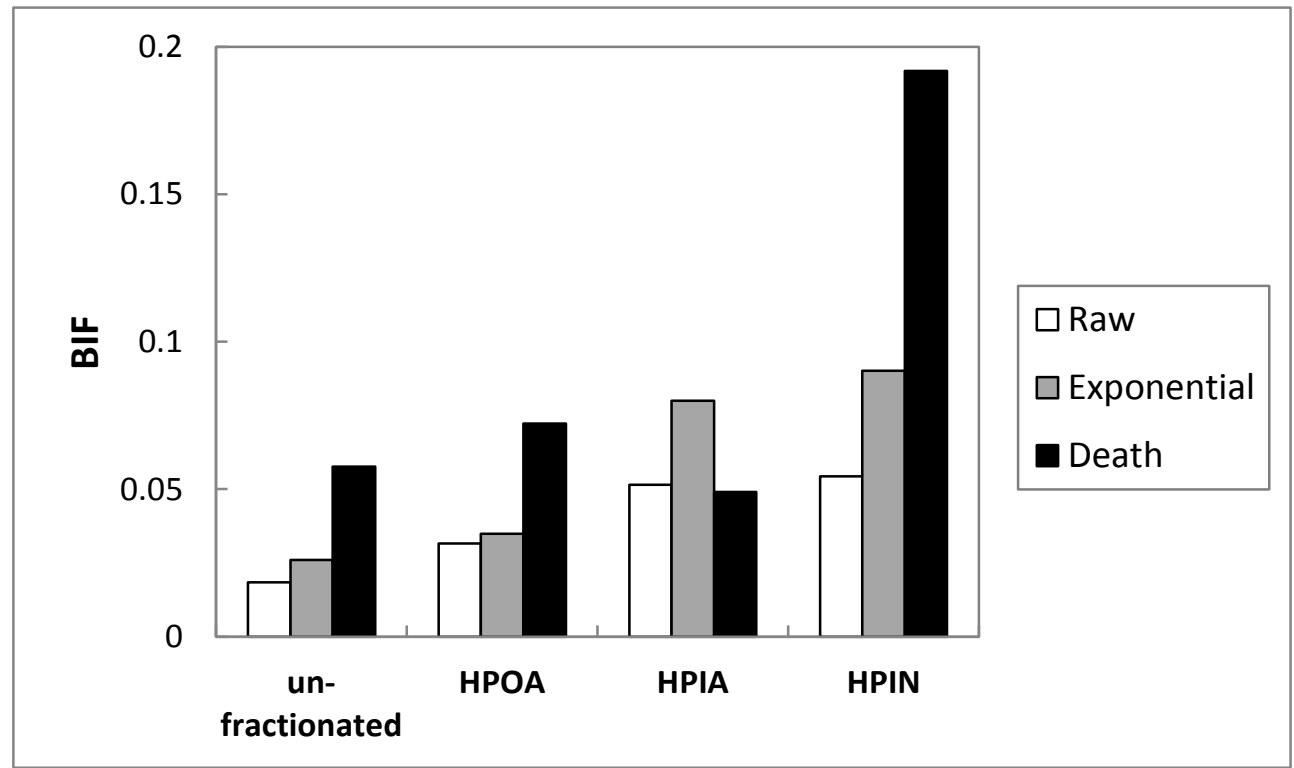

Figure 5. Bromine incorporation factor (BIF) for unfractionated and HPOA, HPIA and HPIN fractions associated with the raw, exponential growth phase and death phase samples. 